\title{
EFFECT OF COLD WORK ON THE RECRYSTALLIZED GRAIN SIZE IN A PARTICLE-REINFORCED
} ALUMINUM ALLOY

\author{
(Received May 22, 1992) \\ (Revised June 23, 1992)
}

G. M. Vyletel, P. E. Krajewski, D. C. Van Aken, J. W. Jones, and J. E. Allison*

Department of Materials Science and Engineering, The University of Michigan, Ann Arbor, Michigan, 48109-2136

*Research Staff, Scientific Research Laboratories, Ford Motor Company, Dearborn, Michigan 48121

\section{Introduction}

Grain size control in engineering alloys is often achieved by minor alloying additions to affect subgrain growth. Recrystallization in these systems is fairly well understood, especially in terms of the influence of small second phase particles on the pinning of subgrains (1-3) and stimulation of nucleation of recrystallized grains (3-5). In contrast, recrystallization in metal matrix composites has only recently become the subject of serious investigation. Because the reinforcement phases are significantly larger and present in much higher volume fractions than traditional second phase particles, the influences of these essentially rigid reinforcement phases on nucleation of recrystallization and pinning during grain growth are important issues. Several recent studies (6-11) have considered various aspects of these issues in aluminum alloys reinforced by either $\mathrm{SiC}$ or $\mathrm{Al}_{2} \mathrm{O}_{3}$ particles. These studies have, however, concentrated on high cold or hot-working reductions. In general, the reported grain sizes of metal matrix composites are small relative to unreinforced materials of similar composition and it is often assumed that pinning processes are responsible for this. There has been a tacit assumption in the metal matrix composite community that the growth of large grains is precluded by this particle pinning phenomenon.

The purpose of this study was to investigate the effect of small amounts of cold work on the nucleation rate during recrystallization and to study grain pinning effects in a composite material where the reinforcement is the only effective pinning constituent. In this paper we describe a simple thermomechanical process, similar to that employed by Arzt and Joos (12), which results in large-grained microstructures in particulate reinforced metal matrix composites. The emphasis of this study was placed on obtaining a uniform distribution of large grains by ensuring a low nucleation rate during recrystallization. Under these experimental conditions the final grain size would be limited by impingement of the recrystallized grains rather than particle pinning. A brief review of the pertinent results for particle pinning is provided below.

The ability of a dispersion of inert second phase particles to inhibit grain growth is a well established phenomenon (e.g.13,14) and many models have been put forth to predict the pinned grain size (e.g.15,16). A classical explanation for this behavior was derived by Zener and reported by Smith (15). A maximum pinned grain diameter, D, was determined by balancing the drag force exerted by a second phase particle of radius, $r$, and volume fraction, $f$, with the driving pressure for grain growth and the following relationship was reported:

$$
\mathrm{D}=(4 / 3) \mathrm{r} / \mathrm{f}
$$

However, experimental evidence indicates that this relationship under estimates the effectiveness of particle pinning during grain growth. For example, the study by Tweed, Hansen, and Ralph showed that the pinned grain size was a tenth of the Zener predicted diameter (17). In an attempt to better explain the pinning phenomena, numerous investigations have been performed $(14,16,17)$. Srolovitz and co-authors $(18,19)$ have used Monte Carlo calculations to simulate grain growth in two dimensions (2-D)to examine grain growth in the presence of second phase particles. Hillert (16) has argued, however, that a 3-dimensional (3-D) approach would better explain grain growth in real materials and that the limiting grain size would depend upon the randomness of the particle/boundary intersection. In the limiting case where each grain corner is filled by 
a second phase particle (completely non-random) the pinned grain diameter would be given as :

$$
\mathrm{D}=3.6 \mathrm{r} / \mathrm{f}^{1 / 3}
$$

Monte Carlo simulations of grain growth performed in 3-D by Anderson et. al. (20) resulted in a similar cubed root dependence upon the volume fraction as that predicted by Hillert for the case of non-randomly distributed particles (16). Anderson et. al. (20) showed that the limiting grain diameter was given by:

$$
D=9.0 \mathrm{r} / \mathrm{f}^{0.31}
$$

It is important to realize that these predictions are only relevant in the context of grain growth driven by the reduction of grain boundary surface area and that during recrystallization the second phase particles may not pin the recrystallization front. This non-pinning aspect has been shown in 2-D Monte Carlo simulations of recrystallization (21).

\section{Experimental Procedure}

Materials used in this study were procured from AMAX R\&D, Golden, Colorado. An aluminum based metal matrix composite with 15 volume percent $\mathrm{TiC}$ was produced via the $\mathrm{XD}^{\mathrm{TM}}$ process (22) and subsequently direct chill cast. The matrix composition was $6.28 \mathrm{wt} \% \mathrm{Cu}$ and $0.3 \mathrm{wt} \% \mathrm{Mn}$ which is similar to the commercial aluminum alloy 2219; however, the standard dispersoid-forming elements $\mathrm{Zr}$ and $\mathrm{V}$ were not added. Test coupons 0.4 by 1.7 by $5.0 \mathrm{~cm}$ were used for the recrystallization study. Each test coupon was solution treated at $535^{\circ} \mathrm{C}$ for 2 hours, water quenched and naturally aged for 24 hours prior to cold rolling. Various samples were then cold rolled to reduce the thickness of the test coupon between 1 and $17 \%$ using a Stanat Model TA315 mill with $11.4 \mathrm{~cm}$ diameter rolls. Annealing experiments were conducted at $535^{\circ} \mathrm{C}$, the standard solution treatment temperature, to avoid precipitation of $\mathrm{Al}_{2} \mathrm{Cu}$ particles. Each cold worked coupon was subdivided into three samples and annealed for 100,300 and 1000 minutes.

Samples for optical microscopy were etched using Keller's reagent ( $190 \mathrm{ml}$ distilled $\mathrm{H}_{2} \mathrm{O}, 5 \mathrm{ml} \mathrm{HNO}, 3 \mathrm{ml} \mathrm{HCL}$, $2 \mathrm{ml} \mathrm{HF}$ ). The reported grain diameters were determined by the mean linear intercept method and were measured on a transverse cross-section relative to the extrusion and rolling direction. Experimental errors in the quantitative measurements are reported as uncertainties associated with the mean values and reflect a $95 \%$ confidence interval for the volume fraction of $\mathrm{TiC}$, the TiC particle radius, and the grain size (23). Experimental errors for the grain boudary particle density are reported as two standard deviations assuming Gaussian statistics. Uncertainties in the theoretical pinned grain size were established following a procedure described by Kline and McClintock for calculating uncertainties in single-sample experiments (24). Therefore, the reported uncertainties for the theoretical predictions are also at a $95 \%$ confidence level.

\section{Results}

A TiC volume fraction of $0.15 \pm 0.009$ was determined by a point counting technique. A TiC particle radius of 1.69 $\pm 0.11 \mu \mathrm{m}$ was determined by chemical dissolution of the matrix in an aqueous solution of hydrofluoric acid and direct measurement of the particle diameters. An average grain diameter of $30.7 \pm 2.1 \mu \mathrm{m}$ was measured after the initial solution heat treatment. The grain size of the cold-rolled and solution treated composite was found to be strongly dependent upon the percent reduction in thickness. A fully recrystallized structure was obtained for all of the samples after 1000 minutes at $535^{\circ} \mathrm{C}$ and the measured grain diameters are reported in Fig. 1 as a function of percent cold working. The shortest annealing time (i.e. 100 minutes) was sufficient to fully recrystallize samples deformed in excess of $5.0 \%$ but the grain sizes reported were those measured from samples annealed for 1000 minutes. Furthermore, no evidence of grain growth was observed in these samples when annealed for 300 and 1000 minutes. A grain diameter of approximately $30 \mu \mathrm{m}$, which was equivalent to the initial material, was obtained for annealed samples deformed in amounts less than $3.0 \%$ or greater than $14 \%$. Remarkably large grain sizes were obtained in the narrow range of deformation between 3.0 and $5.0 \%$. A maximum grain size of $530 \mu \mathrm{m}$ was observed at approximately $3.0 \%$ reduction in thickness. The mean grain size and the error associated with the mean are shown in Table I. It is also interesting to note that the density of particles per unit length of grain boundary was twice that observed by drawing a random line through the microstructure, see Table II. Also, the grain boundary particle 

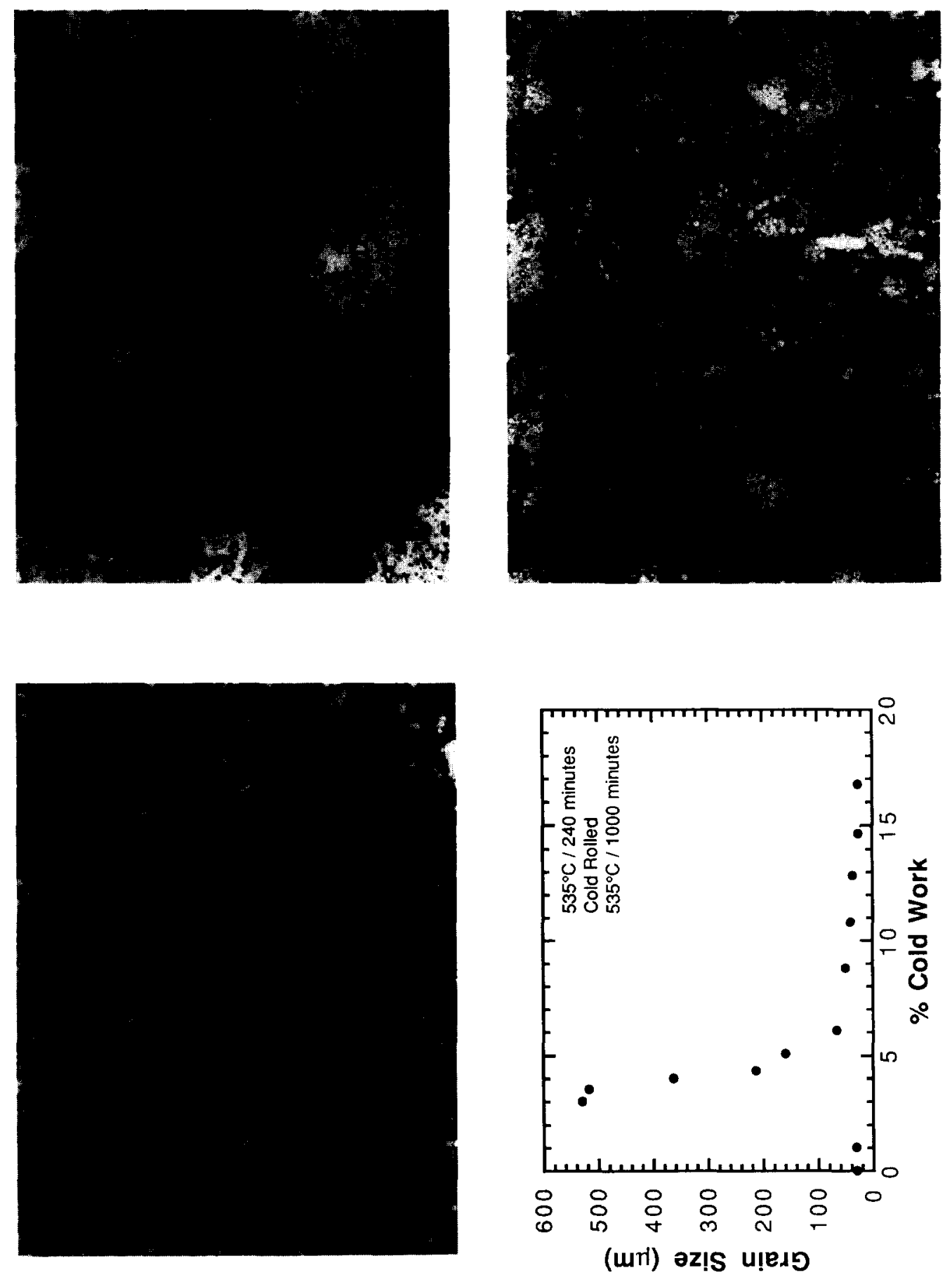

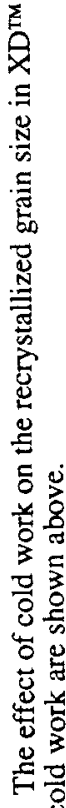

닐 
Table I. Summary of Grain Size Values as a Function of Cold Work

\begin{tabular}{|c|c|}
\hline $\begin{array}{c}\text { Cold Work } \\
(\%)\end{array}$ & $\begin{array}{c}\text { Grain Size } \\
(\mu \mathrm{m})\end{array}$ \\
\hline 0.00 & $30.7 \pm 2.12$ \\
1.02 & $31.4 \pm 2.63$ \\
3.01 & $530 \pm 76.8$ \\
3.52 & $518 \pm 100$ \\
4.01 & $363 \pm 52.0$ \\
4.35 & $213 \pm 41.8$ \\
6.10 & $65.9 \pm 6.56$ \\
8.80 & $49.9 \pm 5.42$ \\
10.82 & $40.8 \pm 2.84$ \\
12.84 & $35.8 \pm 2.61$ \\
14.65 & $25.8 \pm 1.85$ \\
16.77 & $26.2 \pm 3.67$ \\
\hline
\end{tabular}

Table II. Number of Particles per mm of Grain Boundary as a Function of Cold Work

\begin{tabular}{|c|c|}
\hline $\begin{array}{c}\text { Cold Work } \\
(\%)\end{array}$ & $\begin{array}{c}\text { \# of particles / mm } \\
\text { of grain boundary }\end{array}$ \\
\hline 0.00 & $60.4 \pm 6.29$ \\
1.02 & $68.7 \pm 6.90$ \\
3.01 & $69.1 \pm 11.8$ \\
6.10 & $48.8 \pm 6.14$ \\
16.77 & $68.2 \pm 4.08$ \\
Random Line & $33.1 \pm 3.13$ \\
\hline
\end{tabular}

density appeared to be relatively constant with respect to grain size or amount of cold work.

Nucleation density, or grain density, for the recrystallization experiments were calculated following the same assumptions used by Doherty and Martin (1) where the nucleation density was determined as the number of grains per unit volume. The nuclea-

tion density as a function of cold work is plotted in Fig. 2. Also shown in this figure are the nucleation density assuming particle stimulated nucleation where every $\mathrm{TiC}$ particle nucleates a single grain and the nucleation density found assuming a pinned grain diameter predicted from the Anderson et al. (20) model. In addition, theoretical values for the pinned grain diameter were calculated using Zener's original formulation (eq.1), Hillert's 3-D model for non-random particle intersections (eq. 2), and Anderson et al. for 3-D Monte Carlo simulations (eq.3). These values are shown in Table III. The predicted grain diameters and their uncertainties were based on the experimentally determined values for the volume fraction and TiC particle radius using the method of Kline and McClintock (24).

\section{Discussion}

The effect of cold work on the recrystallized grain size in the reinforced aluminum investigated in this study is generally similar to that observed in most metal systems. Above a certain critical strain, extremely large grains can be produced; however, as the amount of strain increases above this critical value the recrystallized grain size decreases. At the critical strain, grains as large as $5 \mathrm{~mm}$ are commonly observed in aluminum alloys (25). The technique of applying small strains and static annealing has been used for many years to produce single crystals and bamboo grain structures in wire samples (e.g. 26). In metal matrix composites, the tendency to increase recrystallized grain size as the amount of cold work is decreased has been observed elsewhere $(6,27)$; however, the occurence of grains larger than the calculated pinned grain size have not been reported previously.

Generally, this result may be understood by considering the relationship between stored energy and the rate of nucleation of recrystallized grains. As the strain energy is increased the nucleation rate increases which leads to smaller grains. Thus, the recrystallized grain diameter decreases rapidly with increasing amounts of cold work. The recrystallized grain size is determined by impingement during the growth of the new grains and primarily depends upon the density and distribution of nuclei formed. In this regard, Humphrey's has shown that with increasing deformation the critical particle size required to nucleate a new grain decreases (4). Thus at low deformations, where only a small number of recrystallized grains are nucleated, it can be envisioned that these nuclei are associated with large particles or clusters of particles. As the deformation is increased a larger fraction of particles will have the potential to act as nucleation sites.

An upper limit in the grain density might be expected under the conditions of particle stimulated recrystallization. In the present case there are $8 \times 10^{6} \mathrm{TiC}$ particles per cubic $\mathrm{mm}$ and if each of these particles nucleated a single grain the resulting recrystallized grain diameter would be approximately $5 \mu \mathrm{m}$. However, the experimental observation is that the 
Table III. Limiting Grain Sizes Predicted by Various Pinning Models

\begin{tabular}{|c|c|c|c|}
\hline Model & Formula & Grain Size $(\mu \mathrm{m})$ & 95\% Conf. Level \\
\hline As-extruded & $-\cdots--$ & 30.71 & \pm 2.12 \\
\hline $16.8 \%$ Cold Worked & $\ldots-\cdots--$ & 26.15 & \pm 3.67 \\
\hline Zener & $4 \mathrm{r} / 3 \mathrm{f}$ & 15.43 & \pm 1.38 \\
\hline Hillert & $3.6 \mathrm{r} / \mathrm{f}^{1 / 3}$ & 11.55 & \pm 0.39 \\
\hline Anderson et. al. & $9.0 \mathrm{r} / \mathrm{f}^{0.31}$ & 27.62 & \pm 1.87 \\
\hline
\end{tabular}

grain size reaches an asymptote of $30 \mu \mathrm{m}$ with increasing amounts of cold work. We speculate that grain growth also occurred in these samples and that the $30 \mu \mathrm{m}$ grain diameter represents a pinned condition for the composite. This appears justified since both the as-extruded and annealed samples exhibit a $30 \mu \mathrm{m}$ grain size. An estimation of the required amount of cold work to obtain a recrystallized grain diameter less than $30 \mu \mathrm{m}$ may be inferred from Fig. 2 . At strains greater than approximately 14 percent cold work the expected recrystallized grain size becomes less than the pinned grain diameter.

It is interesting to note that the experimentally determined pinned grain diameter agrees well with that predicted by eq. 3 as derived from the 3-D Monte Carlo simulations (20), see Table I. Also the experimental result falls outside the 95\% confidence limits for most of the other pinning models. Zener's original model underestimates the pinned grain size by a factor of two, but it should be remembered that this model was based upon a random intersection between grain boundaries and the pinning particles. In this study the grain boundaries have a higher than random density of TiC particles as indicated in Table II. This non-random interaction was predicted by Rollet et al. using 2-D Monte Cario methods to simulate recrystallization (21). Rollet etal. demonstrated that during recrystallization the particles may be overcome by the combined driving forces of the reduction in stored strain energy and the reduction of grain boundary surface energy. However, the particles effectively stop grain growth when driven only by the reduction in surface energy. There may also be an impedance upon grain boundary mobility imposed by the $\mathrm{TiC}$ particles and this may account for the crenulated nature of the observed grain boundaries, see Fig.1. Further studies are being conducted to understand the recrystallization kinetics and these results will be reported elsewhere.

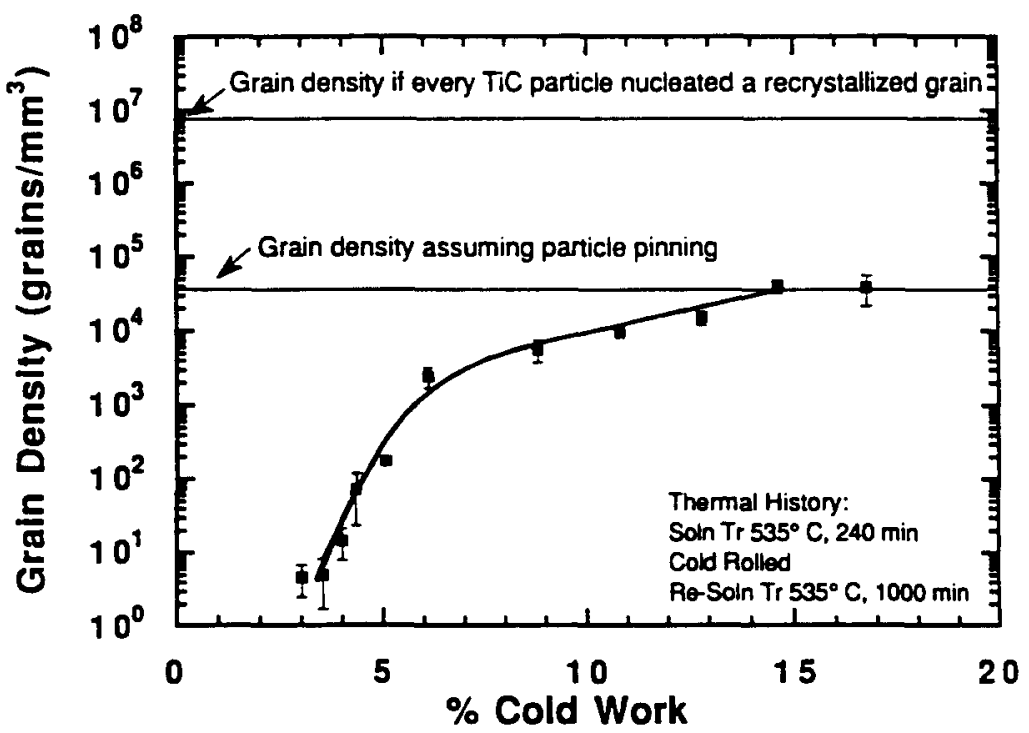

Figure 2. The effect of cold work on the grain density in $\mathrm{XD}^{\mathrm{TM}} 2219 / \mathrm{TiC} / 15_{\mathrm{p}}$. Also shown are the values assuming every $\mathrm{TiC}$ particle nucleated a new grain and assuming particie pinning. 


\section{Conclusions}

It has been shown that the grain size in a particulate reinforced composite may be varied between $530 \mu \mathrm{m}$ and 30 $\mu \mathrm{m}$ using controlled amounts of cold work prior to annealing. The largest grain sizes produced in this study are twenty times the values predicted by the particle pinning models and are larger than any experimentally observed grain sizes in other composite materials with similar volume fractions of reinforcement. It is presumed that particle stimulated nucleation occurs in composite materials even at low amounts of cold work where only the largest particles act as nucleation sites. At reductions greater than $14 \%$ the annealed grain size was limited by particle pinning during subsequent grain growth. It was also found that the best prediction of a pinned grain diameter was calculated from the results of the 3-D Monte Carlo simulations of reference 20 .

\section{Acknowledgments}

This work has been funded by Ford Motor Company. GMV and DCV would also like to thank NSF (contract MSM 8657581) for partial funding of this work.

\section{References}

1. R.D. Doherty and J.W. Martin, J. Inst. Met., 91, 332 (1962).

2. T. Gladman, I.D. McIvor, and F.B. Pickering, J. Iron Steel Inst., 209, 380 (1971)

3. P.R. Mould, and P.Cotterill, J. Mater. Sci., 2, 241 (1967).

4. F. J. Humphreys, Acta Met. 25, 1323 (1977).

5. F. J. Humprheys, in "Recrystallization 90", T. Chandra, Ed., TMS, Warrendale, PA, 113 (1990).

6. Y. L. Lui, N. Hansen and D. J. Jensen, in "Metal Matrix Composites-Processing, Microstructure and Properties", Eds.: N. Hansen, et al., Riso National Laboratory, Roskilde, 1991, p. 67.

7. M. Ferry, P. Munroe, A. Crosky, and T. Chandra, in "Metal Matrix Composites-Processing, Microstructure and Properties", Eds.: N. Hansen, et al., Riso National Laboratory, Roskilde, 1991, p. 337.

8. B. J. Lowe and B. A. Parker, in "Recrystallization 90", T. Chandra, Ed., TMS, Warrendale, PA, 225 (1990).

9. F. J. Humphreys, Mat Sci Eng, A135, 267 (1991).

10. Y. L. Liu, N. Hansen and D. J. Jensen, Mat Sci Tech, Vol 7, 270 (1991).

11. M. Ferry, P. Munroe, A. Crosky, T. Chandra, Mat Sci Tech, in press.

12. E. Arzt and R. Joos, Scripta Met. 23, 1595 (1989).

13. T. Gladman, Proc. Roy. Soc. (London), 294A, 298 (1966).

14. P. R. Rios, Acta Met. 35, 2805 (1987).

15. C. Zener - see C. S. Smith, Trans. Met. Soc., AIME., 175, 15 (1948).

16. M. Hillert, Acta Met. 36, 3177 (1988).

17. C. J. Tweed, N. Hansen, and B. Ralph, Met. Trans 14A, 2235 (1983).

18. D. J. Srolovitz, M. P. Anderson, G. S. Grest, and P. S. Sahni, Acta Met. 32, 1429 (1984).

19. R.D. Doherty, D. J. Srolovitz, A.D. Rollet, and M. P. Anderson, Scripta Met. 21, 675 (1987).

20. M. P. Anderson, G. S. Grest, R. D. Doherty, K. Li, and D. J. Srolovitz, Scripta Met. 23, 753 (1989).

21. A. D. Rollett, D. J. Srolovitz, R. D. Doherty, M. P. Anderson, and G. S. Grest, Acta Met., in press.

22. A. R. C. Westwood, Met. Trans. 19B, 155 (1988).

23. G.F. Vander Voort, ASTM-STP 839 p. 851984.

24. S. J. Kline and F.A. McClintock, Mech Engrg, January 1953, p.3.

25. J.E. Hatch, Aluminum: Properties and Physical Metallurgy, p.122, ASM Int., Metals Park, OH (1984).

26. T.S. Kê, P. Cui, and C.M. Su, Phys. Stat. Sol. (a), 84, 157 (1984).

27. M. Ferry, A. Crosky, P. Munroe, UNSW, Australia, private communication, 1992. 